\title{
Routes of asbestos exposure and the development of mesothelioma in an English region
}

Denise Howel, Lorna Arblaster, Layinka Swinburne, Martin Schweiger, Edward Renvoize, Paul Hatton

\begin{abstract}
Objectives-To investigate the contribution of exposure to asbestos through different routes in the development of mesothelioma.

Methods-Case-control study. 185 confirmed cases of mesothelioma and 160 controls were identified, when death had occurred between 1979 and 1991 in four health districts in Yorkshire. The surviving relatives were interviewed to ascertain lifetime exposure to asbestos. Adjusted odds ratios (ORs) of exposure to asbestos (through occupational, paraoccupational, and residential routes) were calculated for cases and were compared with controls.

Results-Likely or possible occupational exposure to asbestos was more common in cases than in controls (OR 5.6, 95\% confidence interval $(95 \% \mathrm{CI}) 3.1$ to 10.1$)$. After excluding those with likely or possible occupational exposure, likely or possible paraoccupational exposure was more common in cases than controls (OR 5.8, 95\% CI 1.8 to 19.2). Only six cases of mesothelioma were identified as being solely exposed to asbestos through their residence, compared with nine controls. The OR for residential exposure to asbestos varied between 1.5 and 6.6, depending on which potential industrial sources were included, but the $95 \%$ CIs were so wide that slightly reduced or greatly increased odds comparing cases with controls could not be excluded.
\end{abstract}

Conclusion-Study results support previous evidence that occupational and paraoccupational exposure to asbestos is associated with developing mesothelioma. Despite a rigorous search, purely residential exposure seemed to account for only $3 \%$ of identified cases. No firm conclusion can be drawn about the risks from residential exposure alone, as many of the study subjects could also have been occupationally or paraoccupationally exposed to asbestos.

\section{(Occup Environ Med 1997;54:403-409)}

Keywords: malignant mesothelioma; asbestos; nonoccupational exposure

Correspondence to: Denise Howel, Department of Epidemiology and Public Health, The Medical School, Framlington Place,

Newcastle upon Tyne NE2 $4 \mathrm{HH}$

Accepted 18 December 1996
Malignant mesothelioma is an uncommon cancer, often associated with exposure to asbestos, with a latent interval between first exposure and tumour development averaging
$30-40$ years. ${ }^{1-3}$ The death rate is expected to rise in Britain over the next 15-25 years. Although the risks of developing the disease from occupational exposure to asbestos are well established, those due to non-occupational exposure are of increasing concern. This study investigated the contribution of the different routes of exposure to asbestos (table 1) in the development of mesothelioma; concentrating on occupational, paraoccupational, and residential exposure. Over recent years, there has been public concern about the relatively high incidence of mesothelioma locally ${ }^{5}$ occupational risks in three factories which used asbestos in Leeds, Calderdale, and York have been highlighted by the media. This study arose from further publicity about cases labelled as environmental by Her Majesty's Coroner or the local media and which were said to be linked to the Leeds factory. This factory closed in 1958, but considerable concern remains about continuing residential exposure to asbestos in the vicinity of the factory. ${ }^{6}$ There has been recent legal action by some former local residents who have developed mesothelioma without occupational exposure to asbestos. However, many local factories used asbestos, and this study considers exposure to asbestos from all potential sources in the study area.

\section{Subjects and methods}

STUDY SUBJECTS

Potential cases of mesothelioma were sought from the Health and Safety Executive's National Mesothelioma Register, the Yorkshire Regional Cancer Registry, and local postmortem records, where a previous diagnosis of mesothelioma had been made by a local pathologist. Subjects who had died from mesothelioma between January 1979 and December 1991 were considered for inclusion, if the address at death was in the Yorkshire districts of Leeds, Calderdale, York, Wakefield, or Pontefract: these are largely urban areas in the north of England. Two pathologists then independently examined available histological sections from each potential case. Results were classified into definite or possible malignant mesothelioma, or other tumour: only cases agreed to be definite mesothelioma were studied further.

Necropsy records were used to identify controls for the cases. Sets of cases and controls were matched for sex, age at death (to within 10 years), and year of death (to within two years): the sets ranged in size from one case matched with one control, to six cases matched 
Table 1 Routes of asbestos exposure

\begin{tabular}{ll}
\hline Route & Description of exposure \\
\hline Occupational & Takes place at work \\
Paraoccupational (domestic) & Other people working with asbestos who shed it from their clothes or person \\
Incidental exposure & Through hobbies or visits \\
Residential exposure & Living near a particular source of asbestos (mine or factory) \\
General environmental exposure & In the environment without a particular source \\
\hline
\end{tabular}

with five controls. The choice of matched sets rather than matched pairs was considered to make best use of scarce subjects, when some will be dropped from later analyses. Potential controls were excluded if they had died from mesothelioma, or diseases which could have been confused with mesothelioma (bronchial or ovarian cancer), or in circumstances in which gathering information would be difficult (suicide; or if they had been homeless at the time of death; or if they had spent most of their adult life in an institution). This did not give rise to many exclusions. Specimens of nontumorous lung tissue were obtained when available for cases and controls, and were sent for mineral fibre analysis. These results will be discussed elsewhere.

Experience suggested that about 300 cases of mesothelioma would be identified in the study period and area; however, we could only obtain both histological material to confirm the diagnosis and a later exposure history on half of these. Assuming one third of these cases had not been exposed to asbestos through occupational or paraoccupational routes, there was an $80 \%$ power to detect an odds ratio $(\mathrm{OR})=3$ linking residential exposure and mesothelioma at a significance level of $5 \%$.

\section{EXPOSURE HISTORIES}

Attempts were made to contact the next of kin of subjects, and a semistructured questionnaire was used to interview them to obtain a detailed life history of the deceased. It was explained that we were seeking information about the deceased's life history, and they were encouraged to ask other family members or friends for further details. Interviewees were unaware of the main concerns of the study: only the final few questions mentioned exposure to asbestos explicitly. When it was not possible to interview relatives, information was sought from coroner's records. Permission for the study was obtained from local ethics committees.

Coding of exposure histories was performed blind to case-control status, and was based on responses obtained before asking explicitly about asbestos exposure. It was assumed that asbestos exposure in the last 15 years of life (by whatever route) would not have contributed to the development of mesothelioma, and this period was excluded when coding information. Occupational and paraoccupational exposures of less than one month were excluded, as were residential exposures of less than one year.

Occupations were coded with an existing classification $^{7}$ as likely, possible, or unlikely to have led to exposure to asbestos. Each subject was then assigned an overall code, which was the highest level of occupational exposure ever experienced. Appendix 1 lists the jobs which determined the occupational codes of the subjects in the study. Also, the occupations of members of the subject's household were similarly coded, and the subject was assigned an overall code which reflected the highest level of paraoccupational exposure. Any incidental exposure to asbestos-for example, home improvements-was coded likewise.

Factories active from 1900 onwards in north and west Yorkshire considered to use asbestos and which might have emitted asbestos into the environment-for example, through loading, ventilation, or waste disposal-were identified through trade directories and local knowledge. Altogether 278 were identified: many were only active for short periods, and most were within the Leeds or Bradford area. Only 83 of these factories ever had study cases or controls living within $0.5 \mathrm{~km}$ of them. The factories were classified as either group 1 (those where goods containing asbestos were known to be manufactured-for example, engine packing, brake and clutch linings, joints and gaskets, railway carriages, or insulation materials) or group 2 (those where this was in some doubtthat is, the site may have been a warehouse, or asbestos may not have been the material used). Appendix 2 shows the activities at these factories.

A residential history, including schools attended, was obtained at interview. The addresses of subjects within Yorkshire and potential industrial sources were converted, where possible, into the grid references approximating to current postcodes. Distances were calculated between every residential address and every potential source, and then the residential exposure of a subject was coded as: likely if residence was within $0.5 \mathrm{~km}$ of one or more sources at some time; and unlikely if it was not known whether residence was within $0.5 \mathrm{~km}$ of any of these sources during life.

Residential exposure was coded firstly for all potential sources, and secondly for those where manufacture of asbestos goods was more certain (group 1 only). The figure shows the grid references both of addresses where subjects lived and the factories which were potential sources of asbestos to the environment.

\section{STATISTICAL ANALYSIS}

The main technique used for the analysis of the comparative risks of exposure was conditional logistic regression. ${ }^{8}$ Occupational and paraoccupational exposure were coded to three levels -likely, possible, and unlikely. The analyses were carried out with two sets of groupings. Firstly, by comparing likely and possible with the unlikely group, and secondly, by comparing likely with the possible and unlikely groups. 


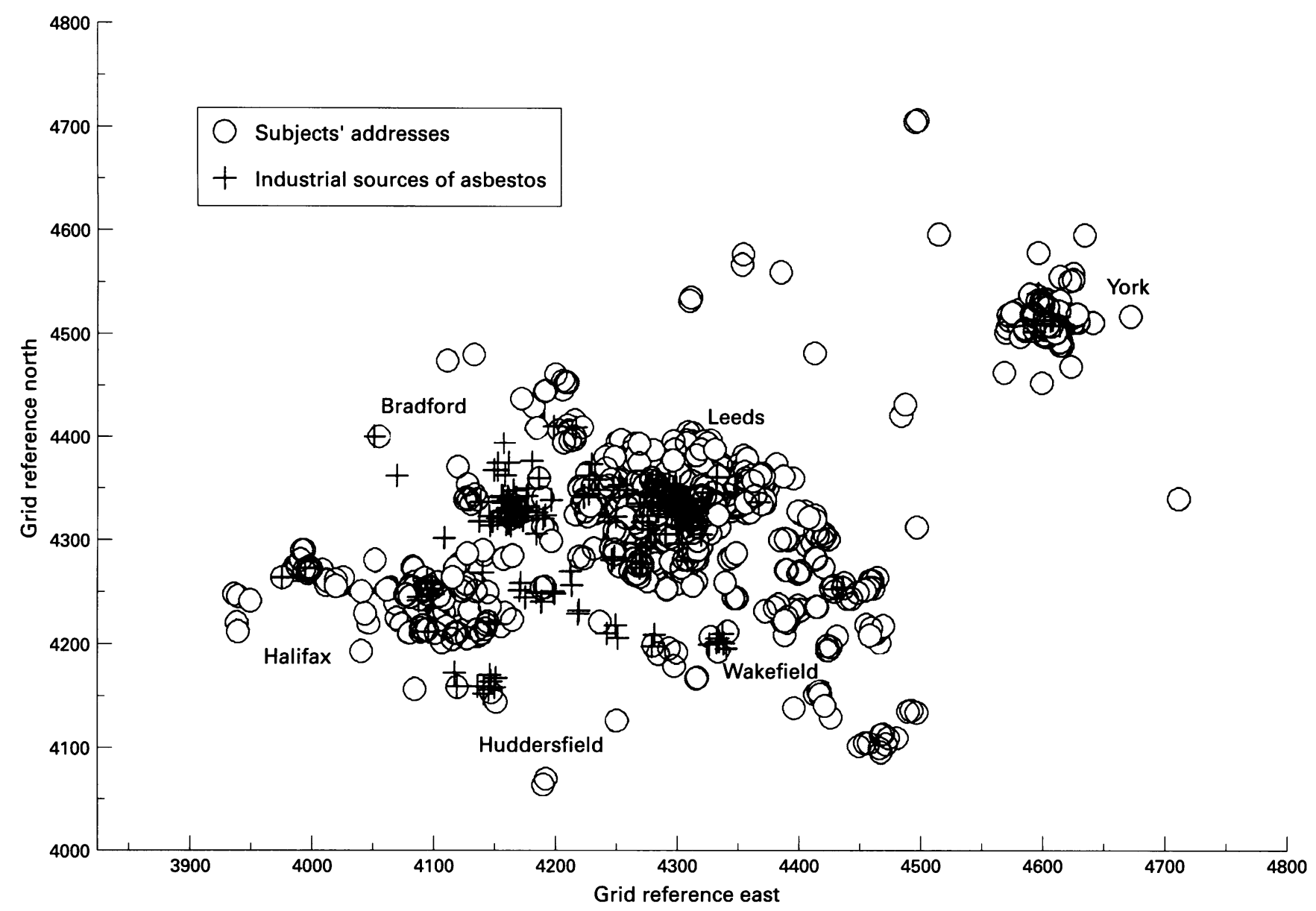

Position of subject addresses and potential industrial sources of asbestos

The conditional logistic model incorporated terms to further adjust for the age, year of death, and district; as the matching criteria were quite wide. The effects of exposure to asbestos by a particular route was evaluated by successively excluding subjects who had been exposed to asbestos by routes which were likely to be at higher levels-for example, excluding occupational exposure while considering paraoccupational exposure. The same matched sets were used for all analyses, but exclusions were made as already described: if all cases in a set were excluded for this reason, the controls in the set were not used.

\section{Results}

There were 316 potential cases of mesothelioma identified: 71 of these could not be confirmed, it was agreed that 15 were not mesothelioma, and four were possible mesothelioma, leaving 226 confirmed cases. The relatives of 133 of these cases were interviewed and information on a further 52 cases was obtained from the coroners' records. Interview information was obtained for all 159 controls.

Table 2 Characteristics of cases and controls

\begin{tabular}{lll}
\hline & Cases $(n=185)$ & Controls $(n=159)$ \\
\hline Age at death (median(range)) & $66(38-89)$ & $67(38-85)$ \\
Men $(\mathrm{n}(\%))$ & $137(74)$ & $118(74)$ \\
Died in $(\mathrm{n}(\%)):$ & $135(73)$ & $122(77)$ \\
$\quad$ Leeds & $22(12)$ & $20(13)$ \\
Calderdale & $19(10)$ & $13(8)$ \\
Wakefield & $9(5)$ & $4(3)$ \\
York & & \\
\hline
\end{tabular}

These were divided into 55 sets of cases and controls. Table 2 shows the distribution of age, sex, and place of death for cases and controls.

\section{COMPARING EXPOSURE TO ASBESTOS IN CASES} AND CONTROLS FOR EACH EXPOSURE ROUTE Overall, $103(56 \%)$ of the cases were classified as likely to have been occupationally exposed to asbestos, compared with $22(14 \%)$ of the controls. Inclusion of those who had possibly been exposed, gives corresponding figures of 150 $(81 \%)$ and $80(50 \%)$. The source of information about occupational history had little association with the exposure category. Among those whose work history came from interview $55 \%$ had likely occupational exposure, $26 \%$ possible, and $19 \%$ unlikely, with corresponding proportions in the cases in which the information came from coroner's records of $58 \%$, $25 \%$, and $17 \%$. In most matched sets the cases had the same or a greater chance of being occupationally exposed than the controls: there were 41 sets where there were a higher proportion of cases than controls who had been likely or possibly occupationally exposed, 11 sets where the proportions were equal, and three sets where there was a higher proportion of controls. Table 3 shows the condtional logistic regression results, and show that the odds on having occupational exposure were considerably higher in cases than controls.

It was considered inappropriate to compare paraoccupational exposure of subjects who have also been occupationally exposed to asbestos. Two analyses have therefore been 
Table 3 Adjusted ORs of asbestos exposure and mesothelioma

\begin{tabular}{ll}
\hline & OR (95\% CI) \\
\hline Occupational exposure: & 9.1 (4.8 to 17.1$)$ \\
$\quad$ Likely $v$ possible and unlikely & $5.6(3.1$ to 10.1$)$ \\
$\quad$ Likely and possible $v$ unlikely & \\
Paraoccupational exposure: & 5.6 (1.9 to 16.5$)$ \\
$\quad$ Excluding subjects with likely occupational exposure: & 1.8 (0.87 to 3.6$)$ \\
$\quad$ Likely $v$ possible and unlikely & \\
$\quad$ Likely and possible $v$ unlikely & $61.7(3.4$ to 1104$)$ \\
Excluding those with likely or possible occupational exposure: & 5.8 (1.7 to 19.2$)$ \\
$\quad$ Likely $v$ possible and unlikely & \\
$\quad$ Likely and possible $v$ unlikely & $1.7(0.78$ to 3.8$)$ \\
Residential exposure: & $2.0(0.9$ to 4.2$)$ \\
$\quad$ Excluding subjects with likely occupational exposure or likely paraoccupational exposure: & $1.9(0.51$ to 7.1$)$ \\
$\quad$ Likely $v$ unlikely (using group 1 sources) & 1.5 (0.46 to 5.1$)$ \\
$\quad$ Likely $v$ unlikely (using all sources) &
\end{tabular}

done: excluding subjects with likely occupational exposure, and excluding those with likely or possible occupational exposure. Altogether 45 matched sets remained, comprising 81 cases and 124 controls, for the first analysis. Eighteen of these cases had likely and five had possible paraoccupational exposure: five of the available controls had likely and 16 had possible paraoccupational exposure. Table 3 shows the adjusted OR estimates. The odds of paraoccupational exposure were higher in cases than controls, whether the possibles were included with the likely or unlikely exposure groups. However, when the possible group was combined with the likely group, the $95 \%$ confidence interval $(95 \% \mathrm{CI})$ for the OR showed that data were also consistent with equal odds of paraoccupational exposure.

Only 27 matched sets, comprising 34 cases and 58 controls, were usable for the second analysis. Of these cases 13 had likely and four had possible paraoccupational exposure; three of the controls had likely and eight had possible paraoccupational exposure. By excluding a further group of subjects who might have been occupationally exposed, we should obtain a less biased estimate of the strength of the association; but the estimate was much less precise, because of the reduced numbers of subjects available. The point estimates of ORs suggested a much stronger association, but were consistent with ORs both little greater than unity and very high indeed. So whereas the odds on paraoccupational exposure were higher for cases of mesothelioma, we are unable to say with any precision by how much they were raised.

Forty four cases and 43 controls reported some activities which could be coded as possible incidental exposure. These included car or motorbike repair, removing fireplaces or walls at home, installing central heating or lagging pipes, dismantling radiators, demolishing a coke oven, and unspecified home improvement tasks. There were three controls for whom this seemed to be the only asbestos exposure, and two cases and five more controls for whom only incidental and residential exposure were identified. The vague exposure descriptions precluded formal analysis.
It was considered inappropriate to compare the residential exposure of cases and controls if they had also been exposed to asbestos by other routes likely to have been at higher exposure levels. Therefore three analyses were carried out: excluding subjects with likely occupational exposure or likely paraoccupational exposure; excluding subjects with likely or possible occupational exposure and likely paraoccupational exposure; and excluding subjects with likely or possible occupational exposure and likely or possible paraoccupational exposure. Table 3 shows the adjusted OR estimates.

Thirty five matched sets comprising 46 cases and 96 controls were usable for the first analysis. Of the 46 cases, 25 had lived within $0.5 \mathrm{~km}$ of any potential source, and 20 in group 1 had lived within $0.5 \mathrm{~km}$ of a potential source. The corresponding figures for the 117 controls were 32 and 24 . There were only 17 matched sets comprising 18 cases and 40 controls who were usable for the second analysis. Of the 18 cases, eight had lived within $0.5 \mathrm{~km}$ of any potential source, and six in group 1 had lived within 0.5 $\mathrm{km}$ of a source. The corresponding figures for the 69 controls were 13 and nine. There were only 14 matched sets comprising 14 cases and 29 controls who were usable for the third analysis. Of the 14 cases, six had lived within $0.5 \mathrm{~km}$ of any potential source, and five in group 1 had lived within $0.5 \mathrm{~km}$ of a potential source. The corresponding figures for the 56 controls were nine and five.

The estimated OR on residential exposure to asbestos comparing cases with controls rose as each of the other sources of exposure was excluded. However, the few subjects remaining without occupational and paraoccupational exposure do not allow us to estimate the strength of the relation between residential exposure and mesothelioma with sufficient precision to rule out either no association or a strong association.

RELATIVE CONTRIBUTIONS OF THE DIFFERENT TYPES OF ASBESTOS EXPOSURE

Altogether $45 \%$ of the exposure histories collected in this study reported asbestos exposure by more than one route. It is impossible to be certain which was the dominant exposure 
Table 4 Main route of exposure for cases and controls (n(\%))

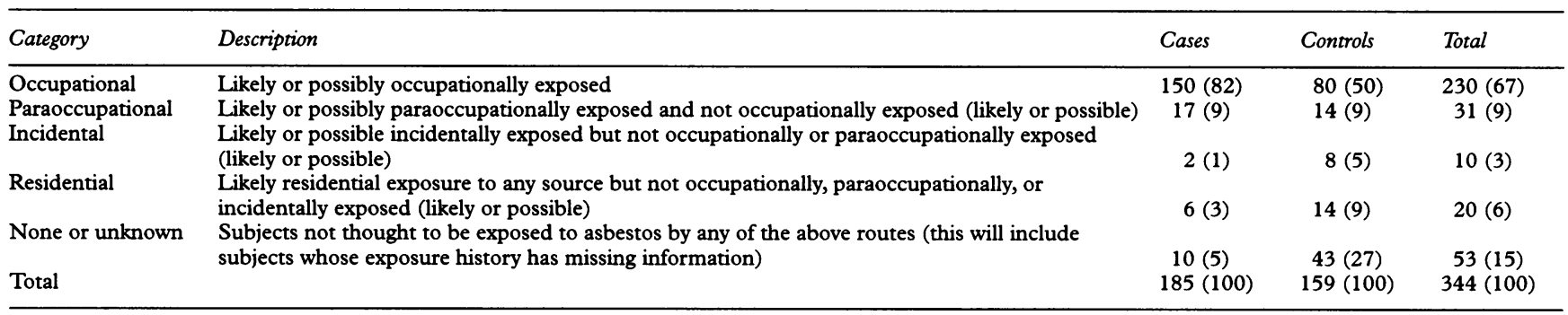

route for each subject; nevertheless, a hierarchy of exposure categories has been suggested. It is assumed that occupational exposure to asbestos has the highest level: lesser exposures are deemed to be paraoccupational, incidental, and residential. Subjects have been grouped into five categories, and table 4 shows the number of cases and controls in each of these. Occupational exposure was the most common route in both cases and controls. Only $5 \%$ of cases seemed to have no exposure to asbestos, whereas the figure was $27 \%$ for the controls.

\section{Discussion}

The hazards of occupational exposure to asbestos have been documented for decades. Wagner $e t a l^{9}$ first established the link between working at, or in close association with, an asbestos mine and development of mesothelioma, and subsequent papers have described the risks associated with other occupations. Of study cases $82 \%$ had likely or possible occupational exposure, compared with $50 \%$ of the controls. Comparisons with other case-control studies are complicated by differing occupational coding schemes, but there were similar proportions of occupational exposure in the cases and controls in a North American study ( $70 \%$ and $51 \%$ respectively), ${ }^{10}$ and fewer so exposed in a London study (41\% and $11 \%) .{ }^{11}$ Our study confirmed that the odds of having a likely or possible occupational exposure to asbestos are significantly higher in cases than controls.

It is generally accepted that there is a link between paraoccupational exposure to asbestos and mesothelioma. Case-control studies in London, ${ }^{11}$ New York, ${ }^{12}$ and North America ${ }^{10}$ found a history of paraoccupational exposure to asbestos in more cases than controls, although the numbers were small. This study supports previous evidence about paraoccupational exposure, but the size and precision of the OR depends on whether we include those possibly exposed with those likely or unlikely to be paraoccupationally exposed.

The risk of residential exposure is less clear. Some case-control studies have investigated the role of residential exposure after excluding other asbestos exposures. The London study found 11 cases compared with five controls living within 0.5 miles of a particular asbestos factory. ${ }^{11}$ The New York study found one case living $1.2 \mathrm{~km}$ from an asbestos factory, and no controls nearby. ${ }^{12}$ The North American study found that one case and four controls had lived within 20 miles of chrysotile mines. ${ }^{10}$ A Connecticut study found that $9.2 \%$ of cases and $9.5 \%$ of controls had lived in the vicinity of an asbestos friction materials plant. ${ }^{7}$ These results are not comparable with each other, or with this study, because of the varying definitions. Outdoor airborne asbestos concentrations were found to be raised near a factory that made asbestos slate board, and near an asbestos-cement plant, ${ }^{13}{ }^{14}$ but in general, little is known about the likely increase in airborne asbestos concentrations near factories that used asbestos, or about the area over which this increase might be expected.

Given the established risks of occupational and paraoccupational exposure, a major focus of our study was the hypothesis that living in the vicinity of a factory that used asbestos is a risk factor for mesothelioma. No study has looked at residential exposure so comprehensively. Many potential industrial sources of asbestos were identified in the study area, as well as the sources which provoked public and media concern. However, only a few sources were near the residences of study subjects, and very few after the exclusion of subjects with occupational and paraoccupational exposure. There were more subjects with occupational or paraoccupational exposure than expected from other studies: this may be because there was genuinely more exposure by these routes in Yorkshire in the study period, or because we obtained more complete exposure histories, or differences in definitions. We had assumed that one third of the cases would have been unexposed through occupational or paraoccupational routes, but the actual figure was $9.7 \%$, leaving relatively few cases available for that part of the study that concentrated on residential exposure. No firm conclusion can therefore be drawn from this study about the risks of residential exposure, because of the small number of suitable subjects. The estimated OR for residential exposure to asbestos varied between 1.5 and 6.6, depending on which subjects and sources were included, but the $95 \%$ CIs were so wide that slightly reduced or greatly increased odds comparing cases with controls could not be excluded.

The $0.5 \mathrm{~km}$ radius from a potential industrial source of asbestos is arbitrary; it is a proxy for exposure from a particular source. It is not assumed that airborne asbestos from the potential source is necessarily found at any residence within $0.5 \mathrm{~km}$. Living close to a source may mean that the subject often walked past it, or played in the factory yard, etc. Also, the identified sources carried out a wide range of industrial activities with asbestos; some were known to process large amounts of raw fibre, 
whereas others may only have stored asbestos goods. The use of trade directories and local knowledge to identify premises used by the asbestos industry may be insufficiently precise. If residents in the vicinity of some of the potential sources were not exposed to asbestos, or only at distances $<0.5 \mathrm{~km}$, their inclusion will underestimate the risk from larger industrial sources of asbestos. However, more detailed information about the manufacturing processes at the various factories is rarely available, preventing more precise estimates of their potential for releasing asbestos into the environment. Nor was it possible to determine which type of asbestos was used in many factories, although the Leeds factory, which had provoked concern, was known to use mainly crocidolite, and the Calderdale factory used crocidolite and brown asbestos (amosite) for long periods. ${ }^{615}$

This and other case-control studies suffer from the fact that retrospective asbestos exposure histories are likely to be incomplete: relatives providing information may not be aware of, or be able to recollect, important occupations or residences, particularly if these were of short duration. The quality of information varied: some informants were able to provide very detailed life histories, others were vague about particular periods or aspects of the subject's life.

There are also difficulties in trying to ascertain the key routes of asbestos exposure when a life history suggests exposure from more than one route. For example, whereas a weaver of asbestos products would almost certainly have been exposed to very high levels of asbestos which would dominate those from other routes, an electrician (coded as possible occupational exposure) might have limited asbestos exposure at work, but higher exposure as the result of living near an asbestos factory, or from a family member working there. We have assumed that occupational exposure dominates that from other sources in this study. The few studies which have measured airborne asbestos concentrations in non-occupational settings indicate that paraoccupational exposure can lead to higher concentrations than residential exposure ${ }^{16}$, but we cannot be sure that this is the case for all the subjects in this study.
This case-control study has brought together detailed histories of asbestos exposures, and has provided valuable information on the risks of occupational and paraoccupational exposure, and made a useful contribution to the study of residential exposure to asbestos. A high proportion of both cases and controls could have been exposed to asbestos at work. Although heavy exposure through the manufacture of asbestos products has fallen over the years, there is still scope for exposure in workers engaged in repair, renovation, and demolition of buildings containing asbestos, the so called "third wave of asbestos disease". ${ }^{17}$ Prevention requires rigorous enforcement of existing legislation, workforce education, and surveillance to ensure that existing standards are adequate to identify other potential causes of mesothelioma. Only 3\% of the cases were associated solely with residential exposure, and it is not possible to conclude from this study alone whether such exposure is a risk factor for development of mesothelioma. A larger study is needed to do this. It is important that all possible sources of asbestos exposure should be considered and thoroughly investigated in cases of mesothelioma. For instance, 25 of the cases of mesothelioma in Leeds between 1971 and 1987 were labelled as due to environmental exposure to asbestos by Her Majesty's Coroner or the local media, but further investigation established that 20 of these could have been occupationally or paraoccupationally exposed. ${ }^{18}$ At present, such investigations are performed on an ad hoc basis, but it would be useful to determine whose responsibility this should be. Combining the results of such inquiries would provide a means of obtaining a sufficiently large database from which the role of residential exposure in the development of mesothelioma in the community could be reconsidered.

\footnotetext{
We are particularly grateful to the contacts of the cases of mes-
othelioma and those who acted as controls, for their help and othelioma and those who acted as controls, for their help and Seacroft and Killingbeck Hospital, for carrying out histological confirmation of the cases. We also acknowledge support given by staff at local pathology laboratories and medical records departments, staff at local offices of Her Majesty's Coroner and staff at the University of Leeds Medical Library, Leeds City Library, and Bradford City Library. The study was funded by the Colt Foundation. There are no conflicts of interest.
}

Appendix 1: List of jobs that determined the classification of subjects into each occupational class of exposure to asbestos.

LIKELY

Asbestos factory worker (fitter, sprayer, carding, packer, mattress maker, maintenance, spinner, etc), boilermaker, bricklayer, builder's labourer, built gas retorts, built railway coaches, display work using asbestos, dockwork involving asbestos, fitter on ships, fitter using asbestos, foreman using asbestos, gas fitter, heating engineer or plumber, joiner using asbestos, laboratory technician using asbestos, lagger, maintenance involving asbestos, metal worker using asbestos, munitions work involving asbestos, naval engineer using asbestos, power station worker, roofer or slater, shipyard worker.

POSSIBLE

Aircraft mechanic, air raid warden, architect, boilerman or stoker, car mechanic, chemist, clerk at asbestos goods factory, cleaner in asbestos goods factory, driver of asbestos loads, electrician, engineer, fireman, fitter, foreman, foundry worker, Hoffman presser, industrial brush repair, 
joiner, laundry worker (ironing), maintenance work, metal worker, munition worker, painter, railway worker, scaffolder, stonemason, tank gunner, telephone engineer, welder.

\section{UNLIKELY}

Baker, barman, catering, cinema manager, cleaner, clerk, clothing industry worker (machinist, tailor's cutter, finisher, etc), colliery worker, draughtsman, driver, dyeworker, factory work, farmwork, film editor, groundsman, hairdresser, laundry worker, letter sorter, manager, navy, nurse, paver, postman, priest, sales assistant, shoemaker, teacher, tiler, upholsterer, warehouseman, wireworker.

Appendix 2: Activities at potential industrial sources of asbestos near Yorkshire residences of study subjects

\begin{tabular}{ll}
\hline & \\
& $\begin{array}{c}\text { Number of sources within } 0.5 \text { km of } \\
\text { \$ 1 study subject }\end{array}$ \\
\hline Group 1-likely manufacture using asbestos: & 17 \\
Asbestos goods manufacturers & 13 \\
Engine packing, steam packing, or metallic packing manufacturers & 7 \\
Brake and clutch manufacturers & 1 \\
Jointing and gasket manufacturers & 7 \\
Railway carriage and locomotive manufacturers & 1 \\
Insulation, boiler covering, or packing manufacturers & 9 \\
Fibrous plaster or fibrous cement manufacturers & \\
Group 2-may be storage only, or asbestos not used: & 10 \\
Asbestos building materials, asbestos cement, asbestos roofing & 18 \\
Insulation specialists, engine packing, fireproofing, steam products manufacturer & 83 \\
Total &
\end{tabular}

1 Talcott JA, Antman KH. Asbestos related malignancy. Current problems in cancer. Chicago year book. Chicago: Medical Publishers, 1988.

2 De Klerk NH, Armstrong BK. The epidemiology of asbestos and mesothelioma. In: Henderson DW, Shilkin KB, Langlois SL, Whitaker D, eds. Malignant mesothelioma. New York: Hemisphere, 1992:223-50.

3 Polnar PV. Further evidence of non-asbestos related mesothelioma. A review of the literature. Scand $\mathcal{f}$ Work Environ Health 1988;14:141-4.

4 Peto J, Hodgson JT, Matthews FE, Jones JR. Continuing increase in mesothelioma mortality in Britain. Lancet 1995; 345:535-9.

5 Gardner MJ, Acheson ED, Winter PD. Mortality from mesothelioma of the pleura during 1968-78 in England and Wales. Br f Cancer 1982;46:81-8.

6 Arblaster L, Hatton P, Renvoize ER, Schweiger MS. Leeds mesothelioma deaths 1971-87. Leeds: Leeds Western Health Authority, Leeds Eastern Health Authority, and Leeds City Council, January 1990.

7 Teta MJ, Lewinsohn HC, Meigs J, Wister V, Romeo A, Mowad LZ, et al. Mesothelioma in Connecticut, 1955-77. f Occup Med 1983;25:749-56.

8 Collett D. Modelling binary data. London: Chapman and Hall, 1991 .

9 Wagner J, Sleggs C, Marchand P. Diffuse pleural mesotheWagner J, Sleggs C, Marchand P. Diffuse pleural mesotheProvince. Br F Ind Med 1960;17:260-71.
10 McDonald AD, McDonald JC. Malignant mesothelioma in North America. Cancer 1980;46:1650-6.

11 Newhouse $M$, Thompson $H$. Mesothelioma of the pleura and peritoneum following exposure to asbestos in the London area. Br F Ind Med 1965;22:261-9.

12 Vianna NJ, Polan AK. Non-occupational exposure to asbestos and malignant mesothelioma in females. Lancet $1978 ; \mathrm{i}$ : 1061-3.

13 Lebel. Review of fibre concentrations in Quebec asbestos mining towns. Quebec: Quebec Asbestos Mining Association, 1984.

14 Kohyama N. Airborne asbestos levels in non-occupational environments in Japan. In: Bignon J, ed. Non-occupational exposure to mineral fibres. Lyon: IARC, 1989:262-76.

15 Edward AT, Whitaker D, Browne K, Pooley FD, Gibbs AR. Mesothelioma in the north of England. Occup Environ Med Mesothelioma in

16 Nicholson WJ, Rohl AN, Weisman I, Selikoff IJ. Environmental asbestos concentrations. In: Wagner JC, ed. Biological effects of mineral fibres. Lyon: IARC, 1980:823-7.

17 Landrigan P. The third wave of asbestos disease: exposure to asbestos in place [preface]. Ann New York Acad Sci 1991;643:15-6.

18 Arblaster L, Hatton P, Howel D, Renvoize E, Schweiger M Swinburne LM. Occupational and environmental links to mesothelioma deaths occuring in Leeds during 1971-87. $f$ Public Health Med 1995;17:297-304. 